\title{
PERBEDAAN UNJUK KERJA MESIN MENGGUNAKAN ELECTRONIC CONTROL UNIT TIPE RACING DAN TIPE STANDAR PADA SEPEDA MOTOR AUTOMATIC
}

\author{
Rifki Mufti Rahman ${ }^{1}$, Dwi Widjanarko², M. Burhan Rubai Wijaya ${ }^{3}$ \\ 1,2,3Pendidikan Teknik Otomotif. Universitas Negeri Semarang \\ Email: rifkikonservasi@gmail.com
}

\begin{abstract}
This research aim to determine the performance difference of using racing electronic control unit (ECU) compared to standard ECU of an automatic motorcycle. The experiment was carried out on a Honda Vario 125cc motorcycle manufactured in 2013. The research methods is experimental research and uses descriptive statistic method. Research findings informs that the maximum torque of the standard ECU is $16.63 \mathrm{Nm}$ at 3500 rpm, and the maximum power is $6.36 \mathrm{KW}$ at $4500 \mathrm{rpm}$. The racing ECU (Iquteche) have a maximum torque of $22.42 \mathrm{Nm}$ at $2500 \mathrm{rpm}$, and maximum power of $7.70 \mathrm{~kW}$. The apparent increase in torque is around $36.58 \%$ and in power is around $33.9 \%$. It can be concluded that the Iquteche ECU provide a more optimized engine performance on an automatic motorcycle.
\end{abstract}

Keywords: ecu, standard, racing, iquteche, power, torque

\begin{abstract}
ABSTRAK
Prestasi mesin sepeda motor berbasis elektronik atau Fuel Injection (FI) memiliki kemampuan atau tenaga yang lebih baik dibandingkan dengan kendaraan sistem konvensional. Penelitian ini bertujuan untuk mengetahui perbedaan unjuk kerja mesin menggunakan Electronic Control Unit tipe racing dan tipe standar pada sepeda motor automatic. Objek penelitian dilakukan pada kendaraan Honda Vario 125cc tahun pembuatan 2013. Penelitian dilakukan dengan menggunkan metode experimental serta analisis data statistik deskriptif. Hasil penelitian menunjukkan bahwa diperoleh data torsi maksimal ECU standar sebesar 16.63 N.m pada putaran 3500 rpm, dan daya tertinggi sebesar $6.36 \mathrm{~kW}$ pada putaran $4500 \mathrm{rpm}$. Sedangkan hasil pengujian menggunakan ECU Iquteche diperoleh torsi tertingi sebesar $22.42 \mathrm{~N} . \mathrm{m}$ pada putaran $2500 \mathrm{rpm}$, dan daya tertinggi sebesar $7.70 \mathrm{~kW}$. Selain itu juga diketahui adanya peningkatan torsi mesin sebesar 36.58\% dan peningkatan daya sebesar 33.99\%, serta diketahui juga bahwa penggunaan ECU Iquteche lebih efektif untuk meningkatkan unjuk kerja mesin pada kendaraan jenis sepeda motor automatic.
\end{abstract}

Kata kunci: ECU Iquteche, torsi dan daya

\section{PENDAHULUAN}

Mesin sepeda motor berbasis karburator sudah bergeser dengan sepeda motor berbasis elektronik. Pada dasarnya prestasi mesin berbasis elektronik atau Fuel Injection (FI) memiliki kemampuan atau tenaga yang lebih baik dibandingkan dengan kendaraan sistem konvensional. Gejala masalah kurang responsif dan bergetar pada motor matic Honda Vario Techno 125 PGM-Fi (injeksi) sering kali dialami ketika usia pakai kendaraan sudah memasuki umur 2 sampai tahun ke 3 (Apewe, 2016). Usia kendaran pada mesin EFI dapat mempengaruhi performa mesin serta konsumsi bahan bakar, namun kondisi ini dapat dikendalikan dengan pengaruh penggunaan ECU. Yunas dan Yuniarto, (2013) mengembangkan kontrol injeksi bahan bakar dan pengapian yang dapat mengoptimalkan pembakaran dalam ruang bakar yang nantinya dapat meningkatkan daya, menghemat penggunaan bahan bakar, mengurangi emisi gas buang dari motor tersebut.

Fahmi dan Yuniarto, (2013) menjelaskan bahwa hasil pengujian menggunakan ECU Iquteche pada kendaraan Yamaha Vixion dapat digunakan untuk mengoptimalkan penggunaan bahan bakar mesin. Pengujian mesin Yamaha Vixion dengan menggunakan ECU Iquteche meningkatkan efisiensi sebesar 11,9\%. 
Peningkatan torsi 0.22 N.m, peningkatan daya 0.2 Hp. Pengaruh mapping pada ECU dapat berpengaruh pada kinerja mesin EFI maka perbedaan ECU yang digunakan pada kendaraan dapat mempengaruhi performa kendaraan tersebut. Rahardjo, (2014) menambahkan, analisa siklus termodinamika sangat penting untuk mempelajari motor bakar. Proses kimia termodinamika terjadi pada motor bakar sangatlah rumit untuk dianalisis.

Proses kinerja mesin dapat disempurnakan dengan penggunaan mapping yang tepat. Fahmi dan Yuniarto (2013) mengatakan salah satu usaha utuk mengoptimalisasi mesin adalah menggunakan ECU. Electronic Control Unit mengontrol kuantitas injeksi dan waktu penginjeksian injektor berdasarkan program spesial untuk menghitung dan menganalisis dari analog dan digital input dari variasi sensor-sensor (Alimin, et.al, 2009: 423).

\section{METODE}

Penelitian dilakukan pada kendaraan Honda Vario 125cc dengan pengujian torsi dan daya menggunakan alat dynotester sportdyno v.3.3. Bahan bakar yang digunakan dalam penelitian tersebut menggunakan jenis Pertamax RON 92 sesuai dengan spesifikasi bahan bakar yang digunakan pada kendaraan Vario 125cc. Pelaksanaan teknik pengumpulan data mengacu pada variabel bebas dan terikat Tabel 1. Hasil Penelitian Torsi

\begin{tabular}{|c|c|c|c|c|c|c|c|c|c|c|c|c|}
\hline \multirow{2}{*}{ Besaran } & \multirow{2}{*}{ ECU } & \multirow{2}{*}{ No. } & \multicolumn{9}{|c|}{ Putaran Mesin (rpm) } & \multirow{2}{*}{$\begin{array}{l}\text { Rata- } \\
\text { rata }\end{array}$} \\
\hline & & & 1500 & 2500 & 3500 & 4500 & 5500 & 6500 & 7500 & 8500 & 9500 & \\
\hline \multirow{8}{*}{$\begin{array}{l}\text { Torsi } \\
\text { (N.m) }\end{array}$} & \multirow{4}{*}{ Standar } & 1 & 14.25 & 15.36 & 16.55 & 12.81 & 9.53 & 7.81 & 6.54 & 3.64 & 2.79 & 9.92 \\
\hline & & 2 & 12.64 & 11.02 & 16.51 & 13.48 & 10.14 & 7.97 & 6.59 & 3.78 & 2.63 & 9.42 \\
\hline & & 3 & 12.17 & 10.68 & 16.82 & 14.22 & 10.62 & 8.18 & 6.73 & 4.3 & 2.91 & 9.63 \\
\hline & & $\begin{array}{l}\text { Rata- } \\
\text { rata }\end{array}$ & 13.02 & 12.35 & 16.63 & 13.50 & 10.10 & 7.99 & 6.62 & 3.91 & 2.78 & 9.65 \\
\hline & \multirow{4}{*}{ Iquteche } & 1 & 18.60 & 22.98 & 20.94 & 16.13 & 12.39 & 9.48 & 7.86 & 6.24 & 4.41 & 13.23 \\
\hline & & 2 & 14.86 & 21.14 & 21.34 & 16.50 & 12.86 & 9.79 & 7.90 & 6.24 & 4.53 & 12.80 \\
\hline & & 3 & 19.31 & 23.14 & 21.30 & 16.57 & 12.53 & 9.70 & 7.91 & 6.38 & 4.86 & 13.52 \\
\hline & & $\begin{array}{l}\text { Rata- } \\
\text { rata }\end{array}$ & 17.59 & 22.42 & 21.19 & 16.40 & 12.59 & 9.66 & 7.89 & 6.29 & 4.60 & 13.18 \\
\hline
\end{tabular}

dimana untuk memperoleh data yang valid perlu dilakukan beberapa tahap agar memperoleh data yang valid.

Tabel lembar pengambilan data yang digunakan untuk mencantumkan hasil pengujian torsi dan daya mesin pada kendaraan Vario 125cc. Data torsi dan daya yang dicantumkan berkelipatan $1000 \mathrm{rpm}$, hal ini dilakukan untuk meningkatkan validitas data yang diperoleh agar hasil analisa data lebih relevan. Teknik analisis data pada pengujian variasi ECU dilakukan menggunakan analisis deskriptif. Sarwono (2006: 138), menyebutkan bahwa statistik deskriptif mengacu pada suatu bentuk yang akan membuat pembaca lebih mudah memahami dan menafsirkan maksud dari data atau angka yang ditampilkan.

Parameter pengujian dipegaruhi oleh penggunaan ECU racing Iquteche jenis Piggyback yang dapat digunakan untuk melakukan mapping. Hasil treatment yang dihasilkan ialah data torsi dan daya. Data tersebut digunakan sebagai perbandingan nilai torsi dan daya pada pengguanaan ECU standar. Indikator yang digunakan untuk membaca nilai torsi dan daya ialah hasil yang diperoleh dari putaran mesin (rpm). Parameter putaran mesin yang digunakan ialah 1500, 2500, 3500, 4500, 5500, 6500, 7500, 8500, 9500 . 


\section{HASIL DAN PEMBAHASAN}

Tabel 1 menunjukkan hasil pengujian torsi kendaraan yang dihasilkan dari eksperimen penggunaan ECU standard dan ECU piggyback Iquteche. Peneitian diambil menggunakan alat uji torsi dan daya dynotester V3.3. Tempat pengambilan data dilakukan di Hyper speed Semarang yang beralamat di jalan Majapahit No. 224 Semarang.

Berdasarkan hasil uji dapat diketahui dari Tabel 1 bahwa torsi tertinggi mesin Vario 125cc dengan menggunakan ECU standar terjadi pada putaran 3500 rpm dengan nilai torsi sebesar 16.33 N.m dan torsi terendah pada putaran 9500 rpm sebesar 2.78 N.m.
Torsi mesin Vario 125cc mengalami peningkatan dengan menggunakan ECU Iqutche dimana torsi tertingi terjadi pada putaran 2500 rpm sebesar 23.42 N.m dan torsi terendah pada putaran 9500 sebesar 4.60 N.m.

Tabel 2 menunjukkan hasil pengujian daya kendaraan yang dihasilkan dari eksperimen penggunaan ECU standard dan ECU piggyback Iquteche. Peneitian diambil menggunakan alat uji torsi dan daya dynotester V3.3. Tempat pengambilan data dilakukan di Hyper speed Semarang yang beralamat di jalan Majapahit No. 224 Semarang.

Tabel 2 Hasil Penelitian Daya

\begin{tabular}{|c|c|c|c|c|c|c|c|c|}
\hline \multirow{3}{*}{$\begin{array}{l}\text { putaran mesin } \\
(\mathrm{Rpm})\end{array}$} & \multicolumn{8}{|c|}{ Daya $(\mathrm{kW})$} \\
\hline & \multicolumn{4}{|c|}{ Standar } & \multicolumn{4}{|c|}{ Iquteche } \\
\hline & 1 & 2 & 3 & rata-rata & 1 & 2 & 3 & rata-rata \\
\hline 1500 & 2.23 & 1.93 & 1.86 & 2.01 & 2.75 & 2.31 & 2.9 & 2.66 \\
\hline 2500 & 3.95 & 2.9 & 2.75 & 3.2 & 5.96 & 5.44 & 5.89 & 5.76 \\
\hline 3500 & 6.04 & 6.04 & 6.11 & 6.06 & 7.6 & 7.75 & 7.75 & 7.70 \\
\hline 4500 & 6.04 & 6.33 & 6.71 & 6.36 & 7.6 & 7.75 & 7.75 & 7.70 \\
\hline 5500 & 5.51 & 5.89 & 6.11 & 5.83 & 7.15 & 7.45 & 7.23 & 7.28 \\
\hline 6500 & 5.36 & 5.44 & 5.59 & 5.46 & 6.48 & 6.71 & 6.63 & 6.61 \\
\hline 7500 & 5.07 & 5.21 & 5.29 & 5.19 & 6.18 & 6.26 & 6.36 & 6.24 \\
\hline 8500 & 3.28 & 3.43 & 3.87 & 3.52 & 5.59 & 5.59 & 5.59 & 5.64 \\
\hline 9500 & 2.83 & 2.6 & 2.9 & 2.51 & 4.39 & 6.1 & 6.5 & 6.17 \\
\hline rata-rata & 4.48 & 4.42 & 4.57 & 4.49 & 5.97 & 5.98 & 3.87 & 6.02 \\
\hline
\end{tabular}

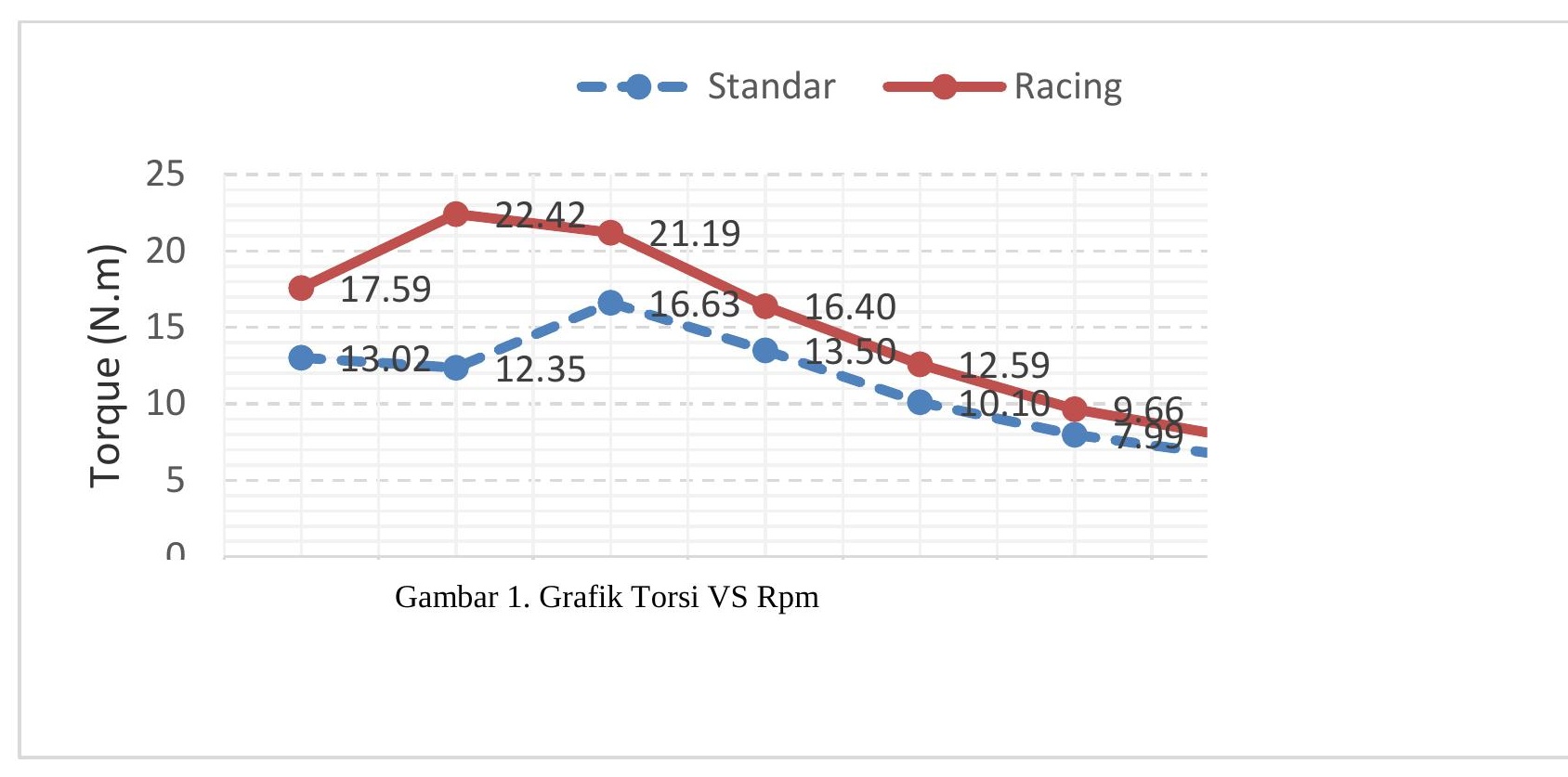


Berdasarkan hasil uji dapat diketahui dari Tabel 2 bahwa daya tertinggi mesin Vario 125cc dengan menggunakan ECU standar terjadi pada putaran $4500 \mathrm{rpm}$ dengan nilai daya sebesar 6.36 kW. Daya mesin Vario 125cc mengalami peningkatan dengan menggunakan ECU Iqutche dimana daya tertingi terjadi pada putaran 3500 rpm sebesar $7.70 \mathrm{~kW}$.
Gambar 1 merupakan visualisasi hasil pengujian Torsi mesin, garis putus-putus merupakan hasil pengujian menggunakan ECU standar dan garis sambung merupakan hasil pengujian menggunakan ECU Iquteche. Berdasarkan grafik tersebut terjadi dinamika perubahan torsi dari putaran rendah ke putaran tinggi.

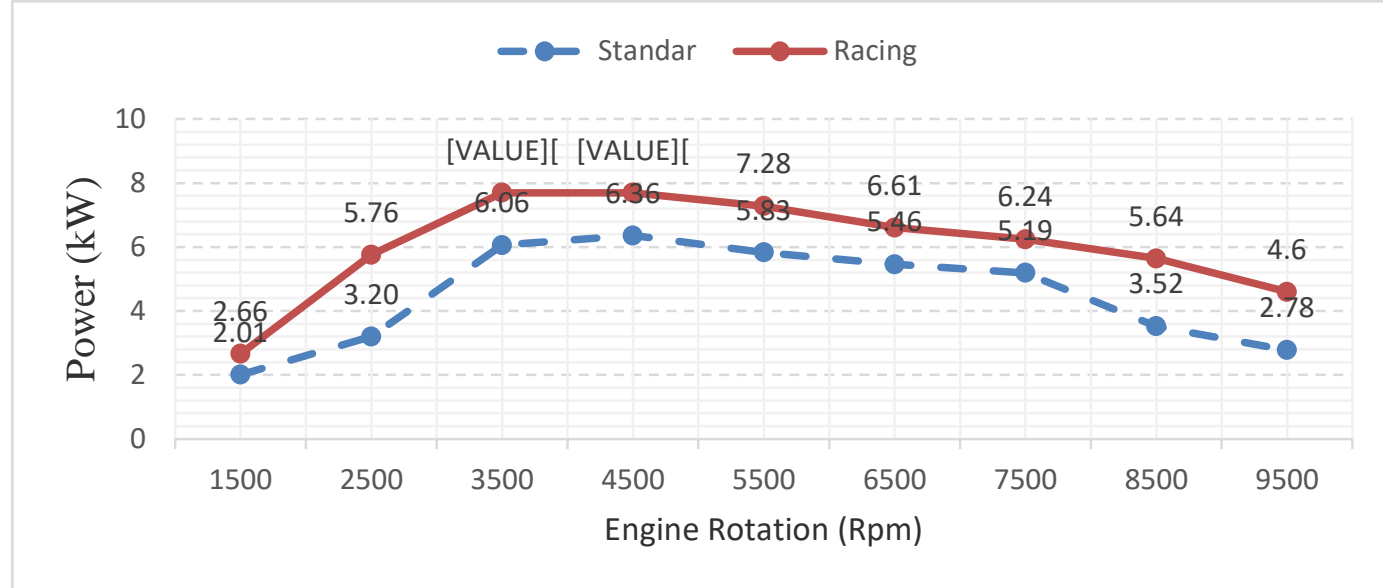

Gambar 2 Grafik Daya VS Rpm

Gambar 2 merupakan visualisasi hasil pengujian daya mesin, garis putus-putus merupakan hasil pengujian menggunakan ECU standar dan garis sambung merupakan hasil pengujian menggunakan ECU Iquteche. Berdasarkan grafik tersebut terjadi dinamika perubahan daya dari putaran rendah ke tinggi.

Hasil pengujian daya menggunakan alat uji dynotester yang telah disajikan Gambar 1.2 tersebut dapat dilakukan uji secara teoritis. Pengujian secara teoritis dilakukan dalam upaya meningkatkan validitas hasil pengujian. Hasil pengujian daya melalui alat uji dynotester seharusnya tidak mengalami perbedaan dengan interval terlalu tinggi. Berikut hasil pengujian daya secara teoritis yang dari kendaraan Vario 125cc berdasarkan persamaan (1).

$$
P(k W)=2 \pi \times N \times T \times 10^{-3}
$$

Keterangan:

$$
\begin{array}{ll}
P & =\text { Daya }(\mathrm{kW}) \\
2 \pi & =3.14 \\
N & =\text { Putaran mesin (rev/s) } \\
T & =\text { Torsi (N.m) }
\end{array}
$$

Perhitungan secara teoritis besar daya yang diperoleh dari output mesin dari kendaraan Vario 125cc dengan menggunakan ECU standar pada pengujian daya tertinggi. Bila putaran mesin $(\mathrm{N})=4500 \mathrm{rpm}=75 \mathrm{rev} / \mathrm{s}$ dan torsi $\mathrm{T}=13.50 \mathrm{Nm}$, maka dengan menggunakan persamaan (1) diperoleh daya sebesar $=6.35 \mathrm{~kW}=8.51 \mathrm{Hp}$

Hasil pengujian daya secara teoritis yang dihasilkan oleh mesin sepeda motor Vario 125cc saat menggunakan ECU standar pada parameter hasil uji daya terendah dengan alat uji dynotest pada putaran 4500 rpm dimana hasil uji secara teoritis sebesar $6.35 \mathrm{~kW}$ sedangkan hasil uji berdasarkan alat uji dynotester sebesar $6.02 \mathrm{~kW}$. Maka dapat disimpulkan bahwa hasil uji daya secara teoritis identik dengan hasil uji daya secara actual.

Perhitungan secara teoritis besar daya yang diperoleh dari output mesin dari kendaraan Vario 125cc dengan menggunakan ECU Iquteche pada pengujian daya tertinggi. Putaran mesin $(\mathrm{N}=3500 \mathrm{rpm}=58.33 \mathrm{rev} / \mathrm{s}, \mathrm{T}$ $=21.19 \mathrm{Nm}$, maka dengan menggunakan 
persamaan (1) diperoleh daya $7,76 \mathrm{~kW}$ atau 10,4 Hp.

Hasil pengujian daya secara teoritis yang dihasilkan oleh mesin sepeda motor Vario $125 \mathrm{cc}$ saat menggunakan ECU Iquteche pada parameter hasil uji daya teringgi dengan alat uji dynotest pada putaran 3500 rpm dimana hasil uji secara teoritis sebesar $7.76 \mathrm{~kW}$ sedangkan hasil uji berdasarkan alat uji dynotester sebesar $7.70 \mathrm{~kW}$. Terdapat perbedaan antara pengujian teoritis dengan hasil dari pengujian dynotest dengan selisih perbedaan $0.06 \mathrm{~kW}$, maka dapat disimpulkan bahwa hasil uji daya (P) secara teoritis identik dengan hasil uji daya $(\mathrm{P})$ secara aktual.

Rata-rata torsi yang dihasilkan oleh mesin Vario 125cc dengan menggunkan ECU standar sebesar 9.65 N.m pada putaran mesin 1500-9500 rpm. Sedangkan rata-rata torsi yang dihasilkan oleh mesin Vario 125cc dari penggunaan ECU Iquteche sebesar 13.18 N.m pada putaran mesin 1500-9500 rpm. Secara keseluruhan torsi pada kendaraan meningkat sebesar $36.58 \%$ dimana pada awalnya rata-rata torsi ECU standar 9.65 N.m dan pada ECU Iquteche sebesar 13.18 N.m. Hal tersebut terjadi karena peningkatan suplai bahan bakar pada mapping ECU Iquteche pada putaran bawah (low). Mapping bahan bakar pada putaran bawah 2000 rpm-3500 rpm dengan prosentase suplai bahan bakar ditingkatkan sebesar 30\%. Torsi merupakan ukuran kemampuan engine untuk menghasilkan kerja (Fahmi dan Yuniarto, 2013). Secara aktual torsi bermanfaat untuk mengatasi hambatan laju kendaraan atau untuk meningkatkan akselerasi kendaraan.

Rata-rata daya yang diperoleh dengan menggunakan ECU standar sebesar $4.49 \mathrm{~kW}$ pada putaran mesin 1500-9500 rpm. Sedangkan rata-rata daya yang diperoleh dengan menggunakan ECU Iquteche sebesar 6.02 pada putaran mesin 1500-9500 rpm. Daya pada kendaraan meningkat sebesar 33.99 \% dimana sebelumnya daya maksimum yang diperoleh pada penggunaan ECU standar sebesar $6.71 \mathrm{~kW}$ dan pada ECU Iquteche sebesar $7.70 \mathrm{~kW}$. Hal tersebut terjadi karena adanya peningkatan torsi yang terjadi. Suplai bahan bakar pada mapping ECU Iquteche pada putaran bawah (low) berdampak pada hasil output mesin. Mapping bahan bakar pada putaran bawah 2000 rpm3500 rpm dengan prosentase suplai bahan bakar ditingkatkan sebesar 30\%.

Penurunan daya yang terjadi pada mesin saat putaran mesin semakin tinggi, hal ini terjadi akibat mapping timming inection yang diutamakan pada putaran bawah. Putaran poros engkol semakin tinggi namun hasil torsi yang menurun pada putaran akhir berdampak pada daya yang dihasilkan. Dimana daya pada putaran akhir semakin menurun. Dalam bukunya Heywood, (1988) menambahkan bahwa daya (P) yang dikirim oleh mesin dan diserap oleh dynamometer merupakan hasil dari torsi dan kecepatan putar. Ali dan Sudarmanta (2012), menambahkan secara teoritis, ketika daya motor meningkat maka daya motor juga meningkat karena daya merupakan perkalian antara torsi dengan putaran poros. Pada hasil pengujian torsi mengalami penurunan pada putaran tinggi, sehingga daya yang diperoleh semakin menurun.

\section{SIMPULAN}

Berdasarkan pengujian unjuk kerja mesin pada kendaraan Vario 125cc dengan perlakuan dengan penggunaan ECU racing, dan bahan bakar yang digunakan jenis Pertamax maka diperoleh kesimpulan sebgai berikut: 1) Terdapat peningkatan unjuk kerja mesin pada kendaraan Vario 125cc dengan penggunaan ECU racing Iquteche yang berpengaruh terhadap torsi dan daya sepeda motor. Data yeng diperoleh ialah Torsi 22.42 N.m dan daya $7.70 \mathrm{~kW}$, dan 2) Terdapat perbedaan unjuk kerja mesin pada kendaraan Vario 125cc dengan penggunaan ECU racing Iquteche yang berpengaruh terhadap torsi dan daya sepeda motor. Data yeng diperoleh telah dianalisa secara deskriptif dimana torsi meningkat sebesar $36.58 \%$ dan daya meningkat sebesar $33.99 \%$. 
Saran yang diberikan adalah bahwa: 1) pengujian unjuk kerja mesin pada kendaraan vario $125 \mathrm{cc}$ dapat meningkat dengan melakukan mapping pada pengaturan low untuk memperoleh penginkatan torsi dan daya pada putaran bawah, dan 2) upaya peningkatan unjuk kerja mesin pada kendaraan vario $125 \mathrm{cc}$ dapat dilakukan dengan menggunakan ECU piggyback Iquteche

\section{DAFTAR RUJUKAN}

Ali, M. Sudarmanta, B. 2012. Perancangan Sistem Pemasukkan Bahan Bakar Secara Injeksi Langsung (Direct Injection) Pada Mesin 650cc dan Pengaruh Rasio Kompresi Terhadap Unjuk Kerja. Teknik POMITS. Vol 1. No 2. ISSN: 2301-9271.

Apewe, M., 2016. Masalah Pada Honda Vario Techno 125 PGM-Fi Brebet, Ngempos dan Bergetar. [Online] Available at: http://newmotic.com/honda-variotechno125-pgmfi-brebet-ngemposbergetar [Accessed 16 June 2017].

Fahmi, F. \& Yuniarto, M. N., 2013. Perancangan dan Unjuk Kerja Engine Control Unit (ECU) Iquteche Pada Motor Yamaha Vixion. JURNAL TEKNIK POMITS, I(1), pp. 1-6.

Heywood, J. B., 1988. Internal Combustion Engine Fundamentals. New York: Mc Graw Hill Book Co. Inc.

Rahardjo, W. D., 2014. Mesin Konversi Energi. Semarng: Unnes Press.

Yunas, M. \& Yuniarto, M. N., 2013. Aplikasi ECU Iquteche Pada Mesin Roadrace 130cc. Jurnal Teknik POMITS, Volume 1. 